\title{
PERANCANGAN AUGMENTED REALITY MEDIA MARKERLES POINT OF INTEREST (POI) DALAM MEMBERIKAN INFORMASI GEDUNG BERBASIS ANDROID (Studi Kasus : Universitas Kristen Satya Wacana)
}

\author{
${ }^{1}$ Abraham Christover Manuputty, ${ }^{2}$ T. Arie Setiawan Prasida \\ Fakultas Teknologi Informasi Universitas Kristen Satya Wacana, Salatiga \\ Jalan Dipnegoro No.52-60 Salatiga, Jawa Tengah 50711 \\ E-mail: 1 christoverabraham@gmail.com,2arie_setiawan_p@yahoo.com
}

\begin{abstract}
Abstrak
Universitas Kristen Satya Wacana (UKSW) merupakan sebuah intuisi pendidikan swasta yang terletak di Salatiga. Setiap intuisi pendidikan tinggi memiliki fasilitas penunjang berupa gedung tempat mahasiswa berkuliah. Melihat permasalahan umum kesalahan gedung perkuliahan yang sering terjadi bagi mahasiswa baru terlebih di UKSW, maka dibangun sebuah aplikasi pencarian lokasi gedung yang dirancang dengan mengacu pada tata letak gedung yang diperoleh melalui google map.Penelitian ini menggunakan teknologi Augmented Reality sebagai media informasi yang digunakan sebagai point of interest dan penanda gedung yang dapat dijalankan pada smarthphone Android.Objek penelitian ini adalah gedunggedung perkuliahan yang ada di UKSW.

Hasilnya adalah aplikasi Find Buildings dapat memberikan informasi mengenai gedung yang dituju secara cepat dan dapat diintegrasikan dengan media promosi konvensional lainnya.
\end{abstract}

Kata Kunci: Universitas, Android, Augmented Reality, Pengenalan Gedung

\section{PENDAHULUAN}

Perkembangan teknologi yang berkembang saat ini sangat pesat.Perkembangan teknologi dapat dimanfaatkan untuk perkembangan pendidikan yang ada di Indonesia.Universitas yang merupakan intuisi pendidikan tinggi dan penelitian tidak lepas dari perkembangan teknologi yang sedang berkembang.Universitas Kristen Satya Wacana merupakan sebuah intuisi pendidikan swasta yang terletak di Salatiga. Setiap intuisi pendidikan tinggi memiliki fasilitas penunjang berupa gedung tempat mahasiswa berkuliah. Bagi mahasiswa baru yang diterima di UKSW dirasa perlu mengenal gedung-gedung yang ada sebagai fasilitas dalam melakukan kegiatan perkuliahan.

Menurut data yang diperoleh dari bagian kemahasiswaan, setiap tahunnya Universitas Kristen Satya Wacana menerima lebih dari 1000 mahasiswa yang berasal dari berbagai belahan Nusantara. UKSW sering disebut Indonesia Mini dikarenakan di UKSW mahasiswa yang diterima tidak menggunakan dialek bahasa Indonesia dalam kehidupan sehari-hari melainkan Maba masih membawa dialek dan budaya dari tempat Maba berasal yang menjadikan aktivitas di UKSW menjadi berwarna.

Hal ini sesuai dengan permasalahan yang terjadi pada umumnya untuk mahasiswa baru (Maba) perguruan tinggi dalam mencari, mengetahui, dan mengenal 


\section{JURNAL INFORMATIKA Vol. 11, No. 2 Juli 2017}

setiap gedung di kampusnya, tak terkecuali dengan Maba di area kampus satu Universitas Kristen Satya Wacana Salatiga (UKSW). Berdasarkan hasil wawancara di lapangan didapatkan hasil $75 \%$ Maba yang berasal dari luar daerah Salatiga yang diterima di UKSW kesulitan untuk menemukan gedung tempat Maba berkuliah. Penyampaian informasi yang didapat mahasiswa selama orientasi tidak cukup efektif untuk mengenal semua gedung yang ada di UKSW dikarenakan kondisi lingkungan kampus satu di UKSW yang sangat luas ditambah lagi mahasiswa yang diterima berasal dari berbagai belahan Nusantara membutuhkan waktu untuk beradaptasi.

UKSW sendiri menggunakan sign system sebagai media informasi gedung. Sign system yang dipasang di lingkungan UKSW tidak cukup efektif karenasign system yang digunakan hanya menunjukkan nama fakultas tidak dengan nama atau kode ruangan yang tertera di Sistem Informasi Akademik Satya Wacana (Siasat), sehingga mengakibatkan banyak mahasiswa terlambat masuk kelas di hari pertamanya. Informasi ini sudah ada dalam buku Orientasi Mahasiswa Baru (OMB) yang dibagikan di awal kuliah dengan ukuran buku yang cukup besar, sehingga mengakibatkan malasnya mahasiswa untuk membawa buku tersebut. Masalah lainnya dari hasil wawancara terhadap mahasiswa didapati sekitar 25\% mahasiswa yang sudah lama berkuliah tidak mengetahui gedung yang ada, karena gedung yang dikenalnya hanya gedung-gedung yang sehari-hari digunakannya saja.

Teknologi Augmented Reality saat ini sudah banyak dikembangkan dan diterapkan di berbagai bidang yaitu kedokteran, hiburan, latihan militer, engineering design, robotics dan telerobotics, consumer design [1].Salah satu metode Augmented Reality yang sedang berkembang saat ini adalah Unity 3D dan Vuforia SDK. Unity 3Dmerupakan sebuah software atau program komputer yang saat ini sedang populer dikalangan game developer atau para pembuat game. Hal yang menarik dari unity 3D adalah kemampuannya dalam mendukung berbagai perangkat teknologi. Vuforia merupakan SDK yang dikembangkan oleh Qualcomm digunakan untuk membantu pengembang dalam menciptakan aplikasi atau game yang memilikiteknologi AR. Vuforia SDK akan memudahkan dan mempercepat pengembangnya dalam membuat aplikasi yang mempunyai teknologi AR karena library dan fungsi-fungsi intinya sudah dibuat oleh Qualcomm. Vuforia memiliki berbagai fitur menarik seperti memindai objek, memindai teks, mengenali bingkai penanda, tombol virtual, mengidentifikasi permukaan objek, mengenali target benda silinder, dan mengenali objek target yang telah ditetapkan [2].

Unity 3D dan vuforia dipilih sebagai dasar pembuatan AR karena memiliki fitur GUI (Graphic User Interface), Audio, Animation, Effect, dan Scripting (Pemograman). Unity 3D mendukung scripting (pemograman) dengan menggunakan berbagai bahasa pemograman diantaranya C\#, JavaScript(UntityScript), dan BOO script [3]. Perancangan AR dalam penelitian ini menggunakan bahasa pemograman C\# dan JavaScript. Penelitian ini memilih penggunaan smartphone karena bersifat fleksibel dan mudah dibawa kemana-mana dan memiliki kemampuan, fitur, dan hardware yang dapat memudahkan penggunanya dalam melakukan pekerjaan seharihari. Berdasarkan data yang diperoleh dari UNICEF Indonesia terdapat 52\% kalangan muda Indonesia menggunakan internet untuk penggunaan smartphone [4].

Metode ini akan digunakan sebagai petunjuk arah bagi mahasiswa yang akan berkuliah di area kampus satu UKSW sehingga dapat memudahkan mahasiswa dalam menemukan gedung dan tidak terlambat di hari pertamanya kuliah. Dengan menggunakan AR dan mobile sensor, gabungan dari dua teknologi ini memiliki 


\section{JURNAL INFORMATIKA Vol. 11, No. 2 Juli 2017}

kemampuan untuk berinteraksi dengan lingkungan.Sumber database geografis dengan informasi konten yang tersedia bisa diakses melalui perangkat ponsel. Teknologi baru tidak hanya meningkatkan pengalaman secara signifikan melainkan meningkatkan metode dalam penyampaian informasi, membuat informasi dapat diakses dalam metode baru dan cara yang menarik.

Melihat permasalahan umum yang sering terjadi bagi mahasiswa baru terlebih di UKSW, maka dari itu dilakukan penelitian tentang AR berbasis lokasi dengan memadukan visualisasi dan konten berbasis peta, memanfaatkan software dan alat pengembangan perangkat lunak Unity 3D dan Vuforia SDK.

\section{TINJAUAN PUSTAKA}

Penelitian yang dilakukan oleh Adhe Wahyu, T. Arie Setiawan P, Ramos Somya dalam jurnal Aplikasi Desain Denah Perumahan Dengan Teknologi Augmented Reality padaMobile Phone berbasis Android OS menghasilkan sebuah aplikasi denah perumahan yang akan mempermudah konsumen dalam memilih rumah idaman dengan cara melihat kemudahan akses yang ditawarkan dari fasilitas perumahan [5].

Kemudian penelitian kedua dilakukan oleh Theofilus Kurniawan Mahasiswa FTI UKSW 2011 dalam jurnal Perancangan Aplikasi Pencarian Lokasi Bengkel Resmi Nasmoco di Kota Semarang Dengan Teknologi Augmented Reality Berbasis Android menghasilkan bahwa pencarian lokasi bengkel Nasmoco telah sesuai dengan data lokasi yang ada. Pada halaman pencarian AR user akan diberikan satu halaman penuh dengan latar belakang gambar hasil tangkapan kamera dan objek Augmented Reality akan ditampilkan diatasnya. Teknologi ini memudahkan pengguna dalam pencarian lokasi bengkel resmi Nasmoco yang terletak dikota Semarang [6].

Penelitian yang dilakukan oleh Edi dengan judul Augmented Reality Gedung Menggunakan Navigasi Marker Dengan Estimasi jarak, menghasilkan bahwa jarak dapat dideteksi melalui luas area marker yang ditangkap oleh kamera.Pada jarak tertentu hingga dideteksi luas marker tertentu akan memunculkan virtual gedung eksterior ataupun interior, menjadikan singlemarker berfungsi seolah-olah multi marker. Meskipun marker dimiringkan, tidak terjadi perubahan yang signifikan terhadap jarak atau luas yang dideteksi oleh aplikasi. Jarak optimum yang dideteksi kamera adalah saat posisi marker terletak tegak lurus dengan kamera. Dengan demikian, luas area yang dihasilkan menjadi maksimal. Saat marker dimiringkan, akan terjadi penurunan hasil luas area sedikit demi sedikit [7].

Persamaan penelitian sebelumnya dan penelitian yang sedang dijalani saat ini adalah sama-sama menggunakan AR serta pencarian lokasi gedung menggunakan GPS menggunakan metode kualitatif sebagai landasan perancangan media informasi gedung. Perbedaan penelitian diatas dengan penelitian yang dilakukan saat ini adalah gedung-gedung yang ada di UKSW sangat beragam serta informasi yang ditampilkan berupa nama gedung, kode ruangan, dan informasi-informasi lain sebagai overlay berbeda dengan penelitian di atas yang hanya memberikan informasi mengenai nama gedung saja.

Augmented Reality (AR) adalah konsep pelapisan konten visual seperti grafik di atas pemandangan dunia nyata seperti yang terlihat melalui sebuah kamera. AR mentransformasi perangkat mobile ke dalam sesuatu yang digambarkan sebagai suatu cermin ajaib sehingga akan terjadi interaksi dengan dunia nyata [8].

Teori Ronald T. Azuma (1997) mendefinisikan augmented reality sebagai penggabungan benda-benda nyata dan maya di lingkungan nyata, dan terdapat integrasi 


\section{JURNAL INFORMATIKA Vol. 11, No. 2 Juli 2017}

antarbenda dalam tiga dimensi, yaitu benda maya terintegrasi dalam dunia nyata. Penggabungan benda nyata dan maya dimungkinkan dengan teknologi tampilan yang sesuai, interaktivitas dimungkinkan melalui perangkat-perangkat input tertentu, dan integrasi yang baik memerlukan penjejakan yang efektif.

Arsitektur Augmented Reality pada tahun 1994 Milgram dan Kishino merumuskan kerangka kemungkinan penggabungan dan peleburan dunia nyata dan dunia maya ke dalam sebuah kontinuum virtualitas.

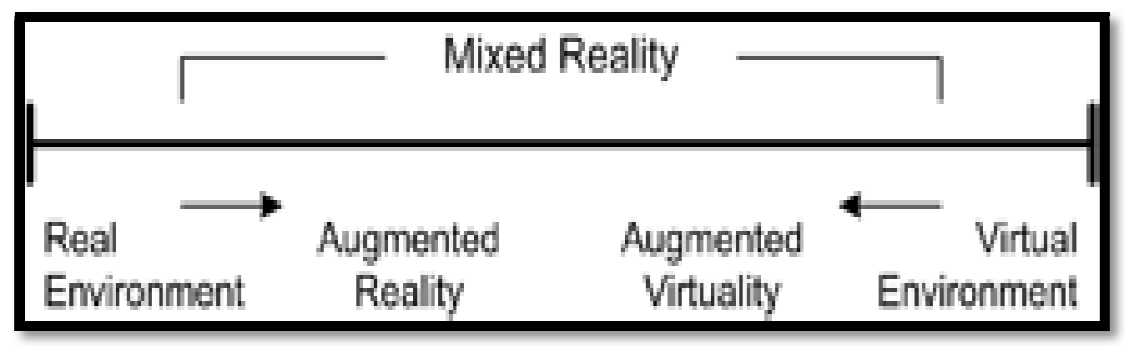

Gambar 1.Virtuality Continuum oleh Milgram dan Kishino (1994)

Dalam kerangka diatas, Augmented Reality lebih dekat ke sisi yang paling kiri yang menjelaskan bahwa lingkungan nyata yang hanya berisi benda nyata, dan sisi paling kanan adalah lingkungan maya yang berisi benda maya. Dalam realitas tertambah, yang lebih dekat ke sisi kiri, lingkungan bersifat nyata dan benda bersifat maya, sementara dalam augmented virtuality atau virtualitas tertambah, yang lebih dekat ke sisi kanan, lingkungan bersifat maya dan benda bersifat nyata. Realitas tertambah dan virtualitas tertambah digabungkan menjadi mixed reality atau realitas campuran [9]. Android adalah sistem operasi yang berbasis Linux untuk telepon seluler seperti telepon pintar dan komputer tablet yang bersifat open source. Sistem Operasi ini diakusisi oleh Google dari perusahaan Android Inc. dan terus dilakukan pengembangan sampai sekarang [10]. Markerlesaugmented reality, merupakan sebuah teknologi yang berkembang saat ini, dengan metode ini pengguna tidak perlu lagi mencetak sebuah marker untuk menampilkan elemen-elemen digital. Dalam hal ini, marker yang dikenali berbentuk posisi perangkat, arah, maupun lokasi (Prihartono, Dhika.2013).

GPS Based Tracking pengembangan teknik ini lebih diarahkan pada smartphone, karena teknologi GPS dan kompas yang tertanam pada smartphone tersebut. Dengan memanfaatkan fitur GPS yang berfungsi sebagai penentu lokasi pengguna pada saat itu berada sehingga lokasi terdekat yang ingin dituju dapat dilihat melalui implementasi augmented reality. Teknik ini berguna sebagai pemandu selayaknya fungsi GPS, namun dilengkapi dengan marker informasi arah yang dituju.Dalam implementasinya, teknik ini mengharuskan tersambungnya koneksi GPS dan kebutuhan paket data yang ada pada smartphone, karena data-data lokasi yang dimiliki GPS memiliki akses langsung dari satelit agar cepat mendeteksi wilayah yang telah dijadikan sebuah objek marker informasi pada Augmented Reality.Akses internet memiliki fungsi sebagai pemanggilan data-data berupa latitude, longitude, serta informasi yang mendukung setiap lokasi yang disimpan pada server sehingga beban ukuran aplikasi dapat diminimalisir.

Teknik GPS based tracking sebenarnya membutuhkan peran kompas dan akselerometer sebagai pengatur ukuran layar secara horizontal dan vertikal agar marker lokasi dapat dilihat ketika kamera handset berada posisi yang sesuai dengan lokasi 


\section{JURNAL INFORMATIKA Vol. 11, No. 2 Juli 2017}

tersebut. Namun ketika handset tidak berada dalam sudut pandang lokasi tersebut maka marker tersebut tidak akan tampak [11].

\section{METODE PENELITIAN}

Metode penelitian yang digunakan dalam penerapan teknologi AR adalah metode kualitatif. Pendekatan kualitatif bersifat fleksibel sesuai dengan kondisi lapangan dengan pengambilan data berupa wawancara. Tahapan-tahapan penelitian dalam penelitian ini mengacu pada strategi linear. Tahapan tersebut dapat dilihat pada Gambar 2.

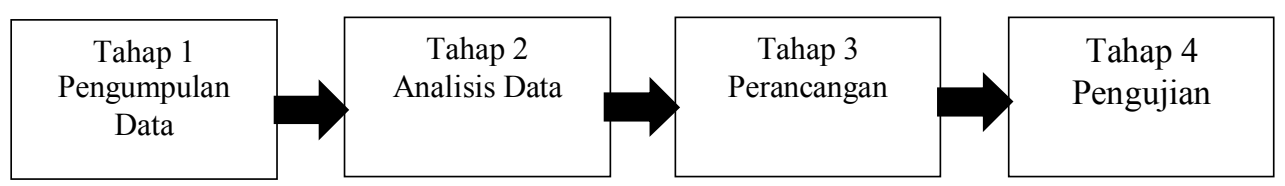

Gambar 2.Tahapan Penelitian

Tahap pertama yang dilakukan adalah pengumpulan data. Proses pengumpulan data dilakukan melalui proses wawancara kepada mahasiswa baru angkatan 2016 yang sedang menjalani proses berkuliah selama satu semester di UKSW, dan didapatkan hasil sebagai berikut:

a. Dalam wawancara terhadap mahasiswa baru 2016 data yang didapatkan berupa masalah dimana Maba kesulitan menemukan gedung perkuliahan karena lingkungan UKSW yang luas dan dipenuhi oleh pepohonan.

b. Sign system yang belum tersedia ketika Maba mulai berkuliah sangat menyulitkan Maba dalam menemukan gedung perkuliahan dan Maba harus bertanya kepada mahasiswa lain yang sedang berjalan di area UKSW.

c. Sign system yang baru digunakan hanya menunjukkan informasi nama fakultas saja tidak dengan kode ruangan.

d. Ruangan yang sulit ditemukan bersifat kondisional tergantung kode ruangan yang tertera pada Kartu Study Tetap (KST)

Wawancara yang dilakukan adalah wawancara tidak terstruktur, yaitu jenis wawancara bebas dimana peneliti tidak menggunakan pedoman wawancara yang tersusun secara sistematis lengkap untuk pengumpulan datanya. [12]

Tahap kedua yaitu melakukan analisa pada data yang telah didapatkan pada tahapan pertama. Setelah melakukan analisis terhadap data yang telah didapat, terdapat sebuah pemikiran yang menuju pada cara bagaimana menyelesaikan permasalahan yang dialami oleh Maba setiap tahunnya yaitu dengan menggunakan teknologi AR sebagai teknologi yang sedang berkembang dan di kombinasikan dengan Google Maps sebagai media informasi petunjuk arah, konten yang akan ditampilkan pada aplikasi ini meliputi kode ruangan seperti GX, E, F, dan lain sebagainya yang berfungsi sebagai penanda gedung. Informasi yang ditampilkan berupa nama fakultas dan estimasi jarak antara pengguna dan gedung yang dituju. Karakteristik dari konten yang akan dibuat adalah sebuah visualisasi konten yang mudah dipahami sehingga tidak menyulitkan mahasiswa.

Tahap ketiga adalah perancangan konsep penelitian perancangan Augmented Reality yang sedang dilakukan memanfaatkan software dan alat pengembangan perangkat lunak Unity 3D dan Vuforia SDK. Konsep dari perancangan aplikasi ini adalah pengguna dapat mengetahui letak dan estimasi jarak terhadap gedung yang dituju dengan mengklik tombol "Find Buildings". Aplikasi ini secara 


\section{JURNAL INFORMATIKA Vol. 11, No. 2 Juli 2017}

otomatis akan menampilkan marker berupa nama gedung beserta jarak yang ditempuh untuk mencapai gedung tersebut dengan memanfaatkan teknologi GPS. Media berupa pembuatan marker atau penanda yang akan dijadikan sebagai patokan gedung-gedung yang ada di UKSW dibuat melalui Google Maps. Pada tahapan ini peneliti mengambil titik koordinat lokasi gedung yang sudah ditentukan melalui google maps untuk menentukan Point Of Interest (POI) Hasil pemberian marker/ penanda dapat dilihat pada Gambar 3.

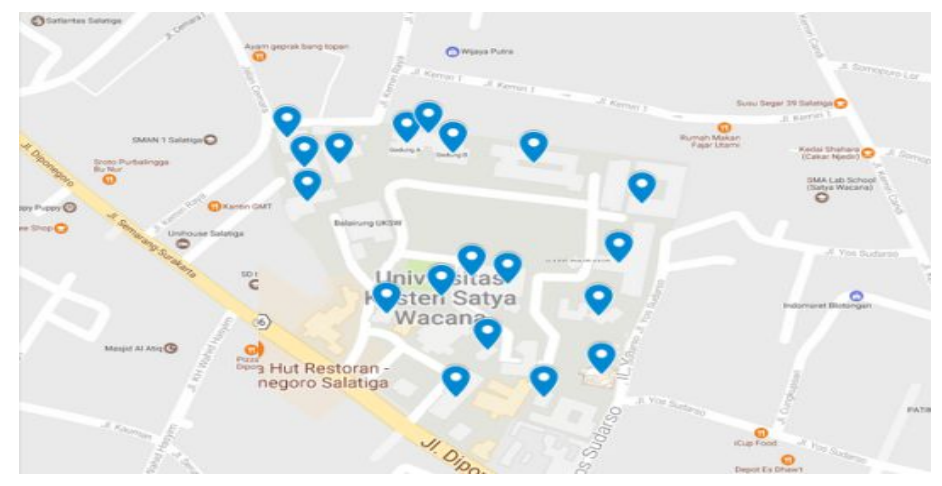

Gambar 3.Marker pada Google Maps

Tahapanselanjutnya adalah pembuatan desain aplikasi "Find Building".Konsep desain aplikasi menggunakan warna-warna pastel.Warna pastel adalah warna yang mengarah ke warna muda dari jenis warna atau warna cerah [13].Warna pastel dipilih karena warna pastel merupakan warna-warna yang soft serta dapat menimbulkan efek sejuk, nyaman, ceria, kalem dan lain-lain sehingga dapat membuat mata nyaman ketika berinteraksi dengan layar smartphone.Typography yang dipilih dalam pembuatan aplikasi ini adalah TypographyjenisArial (Sans Serif). Typographyjenis Arial dipilih karena dapat menimbulkan kesan kontemporer dan bentuk rupa yang efisien dan cenderung digunakan untuk hal-hal yang semi formal dan santai sehingga dapat memudahkan pengguna dalam membaca setiap informasi yang ditampilkan [14].Layout pada aplikasi ini dibuat santai dengan warna pastel dan penambahan ornamen-ornamen traveling yang berkaitan dengan pencarian informasi dan lokasi.Pemilihan warna pada button disesuaikan dengan warna yang ada background.Tahapan selanjutnya adalah scripting (pemograman) untuk menambahkan informasi nama dan estimasi jarak yang dituju dengan menggunakan bahasa pemograman C\# dan JavaScript. Sebuah fitur dasar dari aplikasi AR yang akan dibuat dapat dilihat pada Gambar 4. Merupakan sebuah antarmuka pengguna dengan sebuah database yang sudah dibuat sebelumnya menggunakan media marker POI pada google maps yang akan ditampilkan kepada pengguna. Gambar 4.adalah konsep dasar tentang bagaimana hasil penyajian lokasi Augmented Reality pada aplikasi find buildings.

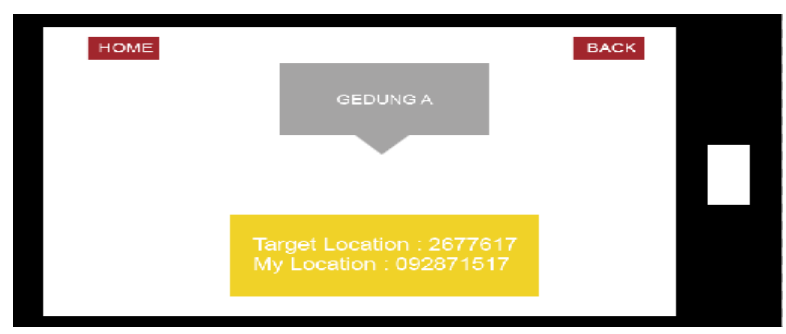




\section{JURNAL INFORMATIKA Vol. 11, No. 2 Juli 2017}

Gambar 4.Point Of interest dalam Augmented Reality

Tahapan selanjutnya adalah tahapan pengujian, dimana akan dilakukan pengujian perancangan aplikasi AR yang telah dirancang kepada 20 Maba UKSW dan 20 mahasiswa yang sudah berkuliah di UKSW dalam kurun waktu 1-2 tahun. Jika pada tahap pengujian ditemukan POI yang tidak sesuai dengan gedung, maka akan kembali dilakukan evaluasi pada pembuatan marker dan POI.

\section{HASIL DAN PEMBAHASAN}

Hasil pembuatan informasi gedung dari penelitian terbagi menjadi 2 bagian yaitu menu awal dan isi konten media informasi. Dibagian menu aplikasi terdapat 3 tombol yaitu find buildings, about, exit. Tombol find buildings untuk memulai pencarian gedung, didalamnya terdapat daftar gedung perkuliahan yang ada di UKSW, tombol about digunakan untuk para pengguna baru atau belum pernah menggunakan aplikasi ini sebelumnya, bertujuan agar pengguna dapat mengetahui cara pemakaian aplikasi dan sumber data yang diperoleh dan mengetahui isi kontenyang sudah disediakan. Tombol exit untuk keluar dari aplikasi find building. Untuk lebih jelas penampilan fungsi da nisi tombol dari menu awal bias dilihat pada Gambar 5.

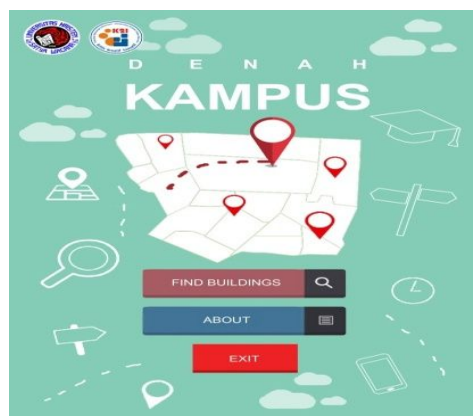

(a)

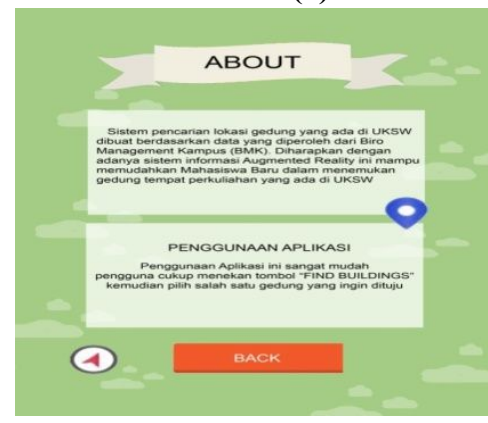

(c)

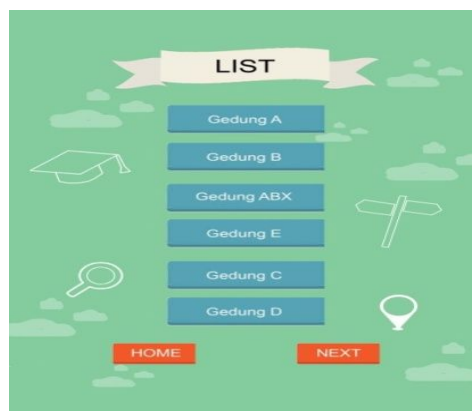

(b)

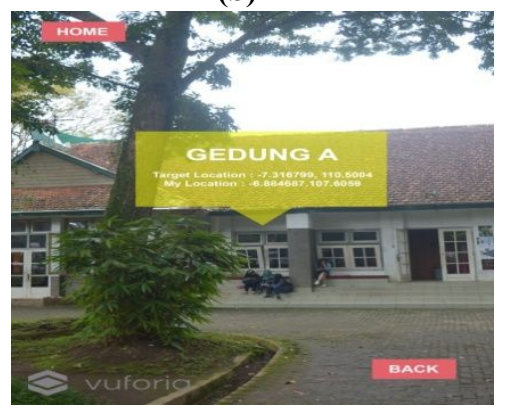

(d)

Gambar 5. (a) Tampilan Menu Awal, (b) Tampilan isi Find Buildings, (c) Tampilan isi About, (d) Tampilan Augmented Reality

Aplikasi Find Bulidings telah diujikan pada Biro Management Kampus (BMK) UKSW didapatkan hasil penempatan POI dan informasi yang diberikan sudah sesuai dengan data base yang dimiliki oleh kampus. Aplikasi ini dapat menjadi alternatif baru dalam penyajian media informasi pencarian gedung dan petunjuk arah dan dapat diterapkan sebagai sarana penyampaian informasi gedung yang ada di UKSW. Pengujian selanjutnya dilakukan kepada 20 responden Maba 2016 yang berasal dari luar daerah Salatiga, didapatkan hasil 80\% penyampaian informasi gedung yang telah dibuat sangat berguna sebagai media penentu arahgedung kuliah yang ada di lingkungan UKSW. Pengujian berikutnya dilakukan terhadap 20 mahasiswa yang 


\section{JURNAL INFORMATIKA Vol. 11, No. 2 Juli 2017}

sudah berkuliah di UKSW dalam kurun waktu 1-2 tahun, didapat hasil bahwa 65\% mahasiswa mengetahui letak dan nama gedung-gedung yang belum pernah mereka ketahui. Pada awal pengujian, mahasiswa diberi kesempatan untuk mencoba aplikasiFind Buildings yang telah dibuat. Tahap selanjutnya dilakukan proses wawancara terhadap mahasiswa untuk mengetahui apakah aplikasi tersebut dapat membantu mereka dalam menemukan gedung kuliah dankonten-konten yang telah dibuat sudah sesuai dengan karakteristik lingkungandan gedung yang ada di UKSW. Dari hasil wawancara, diketahui bahwa aplikasi ini merupakan hal baru sebagai media penyampaian informasi dan petunjuk arah di UKSW. Penyajian informasi melalui aplikasi find buildings lebih informatif dalam menentukan arah gedung-gedung.

\section{KESIMPULAN}

Perkembangan teknologi yang berkembang saat ini dapat dimanfaatkan dalam kemajuan media informasi sebagai aspek penting dalam suatu intuisi pendidikan seperti UKSW, dengan ruang lingkup yang luas dan dipenuhi pepohonan banyak sekali mahasiswa yang kesulitan menemukan gedung tempatnya berkuliah. Berdasarkan hasil pengujian yang telah dilakukan, Find Buildings dapat memberikan informasi lokasi yang akan dituju dan media ini berhasil menyampaikan informasi tentang lokasi dan informasi mengenai gedung yang akan dituju. Media informasi tersebut juga merupakan inovasi yang bisa diterima dengan baik, dan dapat dikembangkan lebih lanjut menjadi bagian dari sistem pencarian gedung bagi pengguna di UKSW. Untuk pengembangan penelitian selanjutnya, diharapkan aplikasi Find Buildings mampu diintegrasikan dengan media lain, seperti virtual reality yang memungkinkan adanya interaktifitas dan informasi yang disajikan lebih variatif.

\section{DAFTAR PUSTAKA :}

[1] STIKOM Binaniaga Bogor

http://www.stikombinaniaga.ac.id/index.php?id=12 $\quad$ (Diakses pada tanggal 8 Desember 2016).

[2] Vuforia https://teknojurnal.com/vuforia/ (Diakses 15 Maret 2017)

[3] Belajar Unity3D-Game Engine http://www.sederhanagulo.com/belajar-unity3d-game-engine.html (Diakses 19 Maret 2017).

[4] UNICEF Indonesia https://www.unicef.org/indonesia/id/media_22169.html (Diakses 27 Febuari 2017)

[5] Adhe Wahyu, T. Arie Setiawan P, Ramos Somya. Jurnal Aplikasi Desain Denah Perumahan Dengan Teknologi Augmented Reality padaMobile Phone berbasis Android OS : Program Studi Teknik Informatika FTI-UKSW

[6] Theofilus Kurniawan, Jurnal Perancangan Aplikasi Pencarian Lokasi Bengkel Resmi Nasmoco di Kota Semarang dengan Teknologi Augmented Reality Berbasis Android : Program Studi Teknik Informatika FTI-UKSW 2014

[7] Edi Ag., Moch.Hariadi. 2010. Augmented Reality Gedung Menggunakan Navigasi Marker Dengan Estimasi Jarak : Program Studi Magister Teknik Elektro, Konsentrasi Teknologi Permainan Fakultas Teknologi Industri, ITS Surabaya.

[8] Damala, A. and Kockelcorn, H. [ed.] departent of Cultural Informatics University of the Aegean. Mytilene,Greece : In Press, 2006, Evaluation strategies for mobile museum guides: a theoretical framework, Third International Conference of Museology: Audiovisuals as Cultural Heritage and their Use in Museums. 


\section{JURNAL INFORMATIKA Vol. 11, No. 2 Juli 2017}

[9] Van Krevelen, DWF \& Poelman.R. A Survey of Augmented Reality, Technologies, Applications and Limitations. The International Journal of Virtual Reality, 2010 9(2) : 1-20.

[10] Speckmann, Benjamin. compsci/projects/Master_Thesis_Benjamin_Speckmann.pdf. http://www.emich.edu. [Online] 2008.

[11] Prihartono, Dhika. (2013). Membuat Aplikasi Game 3D Interaktif Augmented Reality.Surakarta: AR Online.

[12] Lina. 2015. Wawancara Berdasarkan Tujuan Menurut Para Ahli, http://www.ilmupsikologi.com/2015/08/wawancara-berdasarkan-tujuan-menurut-ahli.html (Diakses 5 Desember 2016)

[13] Grafis Media http://www.grafis-media.website/2016/07/pengertian-warna-pastel-dancontohnya.html?m=1 (Diakses pada tanggal 20 Maret 2017)

[14] Sekilas Tentang Typography http://www.wadezig.com/sekilas-tentang-tipografi/ (Diakses pada tanggal 25 Maret 2017) 